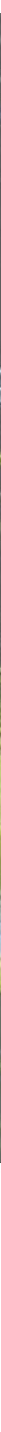




\title{
A FLORESTA E O JARDIM NO BRASIL DO SÉCULO XIX
}

\author{
THE FOREST AND THE GARDEN IN BRASIL AT THE 19TH CENTURY
}

\author{
Solange de Aragão* \\ Euler Sandeville Junior**
}

\begin{abstract}
RESUMO
objetivo deste trabalho é colocar em discussão o processo cultural de transformação da paisagem brasileira no século XIX a partir da destruição de amplas áreas florestadas para cultivo, criação de gado, exploração de minérios e coleta de determinadas espécies da flora e da fauna. Por outro lado, procura-se demonstrar a concomitante difusão e transformação do jardim da casa brasileira, que se europeíza no momento em que a floresta se torna símbolo do nacionalismo - jardim este cultivado não apenas na área urbana, mas também junto às construções implantadas nas áreas desmatadas da floresta. Para isto, adotamos como ponto de partida obras como A ferro e fogo: a história e a devastação da mata atlântica brasileira (1996), de Warren Dean, e Sobrados e mucambos e Nordeste (1936), de Gilberto Freyre, considerando ainda, na análise, os relatos de viagem do século XIX e textos da literatura brasileira que tratam da transformação da paisagem neste período.

Palavras-chave: História da paisagem brasileira. Século XIX. Floresta. Jardim da casa brasileira. Transformação da paisagem.
\end{abstract}

\begin{abstract}
The aim of this work is to bring into discussion the cultural process of transformation of the brazilian landscape during the 19th century which stemmed from the destruction of large forest areas for cultivation, animal husbandry, mineral exploration, and collection of certain species of flora and fauna. On the other hand, we intend to demonstrate the concomitant diffusion and transformation of the garden of the Brazilian house that incorporated some European aspects at the moment the forest became a symbol of nationalism, being traditionally cultivated not only in urban areas but also close to buildings situated at forest cleared areas. With this purpose, we adopted as the starting point works such as With broadax and firebrand:
\end{abstract}

* Arquiteta e urbanista pela Faculdade de Arquitetura e Urbanismo da Universidade de São Paulo (FAUUSP). Mestre em Estruturas Ambientais Urbanas e doutora em Paisagem e Ambiente pela FAUUSP. Pós-doutorados em História do Brasil, pela Faculdade de Filosofia, Letras e Ciências Humanas da Universidade de São Paulo (FFLCH-USP) e em Arquitetura e Urbanismo pela FAUUSP. Professora doutora de Planejamento Paisagístico da Universidade Nove de Julho (UNINOVE). Autora de Ensaio sobre o jardim (Global, 2008) e Ensaio sobre a casa brasileira do século XIX (Edgard Blücher, 2011). escritoepaisagem@hotmail.com

** Arquiteto e urbanista, arte-educador, pós-graduado em Ecologia, mestre e doutor em Estruturas Ambientais Urbanas pela Faculdade de Arquitetura e Urbanismo da Universidade de São Paulo (FAUUSP). Professor livre-docente do Departamento de Projeto da FAUUSP, vice-coordenador da Área Paisagem e Ambiente do Programa de Pós-graduação em Arquitetura e Urbanismo da FAUUSP, professor do Programa Interdisciplinar de Pós-Graduação em Ciência Ambiental da USP, coordenador do Laboratório Espaço Público e Direito à Cidade (LabCidade) da FAUUSP.

esandeville@gmail.com

http://espiral.net.br 
the destruction of the Brazilian Atlantic forest (1996), by Warren Dean, as well as The mansions and the shanties and Northeast (1936), by Gilberto Freyre, taking into account also travel writings and texts from Brazilian literature which deal with landscape transformation at this period.

Keywords: History of the brazilian landscape. 19th century. Forest. The garden of the brazilian house. Landscape transformation.

\section{INTRODUÇÃO}

Escrever sobre a floresta e sobre o jardim da casa brasileira do século XIX é escrever sobre um dos mais amplos e abrangentes processos de transformação da paisagem brasileira'; é tratar da passagem de uma paisagem nem sempre natural, posto que, muitas vezes, humanizada, para uma paisagem cultural, das fazendas, dos sítios, das chácaras, das vilas e dos povoados, da área tornada urbana.

A floresta, que, originariamente, cobria parte considerável do território brasileiro, antes da descoberta pelos europeus, vai, ao longo dos séculos, cedendo lugar para espaços vazios, depois da derrubada do pau-brasil, para plantações e culturas diversas, para o estabelecimento de complexos agrícolas, terras de pastoreio, cidades e povoações, onde surge a figura do jardim, quase sempre junto às construções. Inicialmente, um jardim muito simples, sem qualquer ordem ou requinte, onde tudo se misturava - flores e ervas, legumes e árvores de fruto.

O século XIX é marcado pela expansão das áreas devastadas de floresta para o plantio do café e o desenvolvimento de outras culturas e, simultaneamente, pela difusão e transformação do jardim da casa brasileira ${ }^{2}$. Ao mesmo tempo em que se propaga uma exaltação da natureza brasileira, com o romantismo, e que a floresta se torna símbolo do nacionalismo, grandes áreas florestadas são destruídas com danos irreversíveis à paisagem. Por outro lado, e da mesma forma de modo muito contraditório, enquanto se exaltam as belezas naturais do país, difunde-se o jardim de rosas, de camélias e

Não se trata, aqui, de explorar a relação milenar e complexa entre o jardim e a floresta, mas de abordar o caso específico de transformação da paisagem brasileira no século XIX, no que concerne à vegetação: se, por um lado, as florestas nativas eram postas abaixo por uma série de motivos registrados neste artigo, por outro lado, difundia-se o jardim da casa brasileira com espécies predominantemente exóticas neste período.

2 "O jardim da casa brasileira, enquanto conservou a tradição do português, foi sempre um jardim sem a rigidez dos franceses ou dos italianos; com um sentido humano, útil, dominando o estético. Irregulares, variados, cheios de imprevistos. [...] Várias plantas eram cultivadas neles sem motivo decorativo nenhum: só por profilaxia da casa contra o mau-olhado: o alecrim e a arruda, por exemplo. [...] Outras plantas eram cultivadas principalmente pelo cheiro bom; pelo 'aroma higiênico' [...]: o resedá, o jasmim-de-banha, a angélica, a hortelã, o bogari, o cravo, a canela. [...] Ainda outras plantas se cultivavam no jardim para se fazer remédio caseiro, chá, suadouro, purgante, refresco, doce de resguardo: a laranjeira, o limoeiro, a erva-cidreira. [...] Muita planta se tinha no jardim só pela cor sempre alegre das suas flores [...]" (FREYRE, 2006, p. 320). Observe-se que a maior parte das plantas do jardim da casa brasileira mencionadas por Freyre é exótica (ARAGÃO, 2008, p. 79-80). A leitura dos diversos relatos de viagem do século XIX, bem como dos anúncios de jornal, revela esta mesma caracterização do jardim da casa brasileira - com o predomínio do sentido útil sobre o estético: "Aluga-se huma caza de vivenda $n^{\circ} 4$, no caminho novo do Botafogo [...]; tambem o jardim que está bem plantado com Laranjeiras [...]." Diário do Rio de Janeiro, 07 de janeiro de 1822, acervo da Fundação Biblioteca Nacional. Disponível em: <http://memoria.bn.br/pdf/094170/per094170_1822_0100005.pdf>. Acesso em: 29 jul. 2013). "[...] eventualmente, planta-se um jardim num trecho do quintal, raramente com esmero e bom gosto, preferindo-se cultivar as folhagens e flores europeias, ao invés das esplêndidas e ornamentais plantas da região." (WALLACE, 1979, p. 20). 
de outras flores exóticas, muitas vezes, com traçado à europeia, junto aos chalés e a outras construções ecléticas:

[...] é da segunda metade do século passado em diante [século XIX] que as áreas ajardinadas se multiplicam, crescem e passam a constituir um elemento ponderável no conjunto das edificações e dos espaços vazios da cidade brasileira. Surge um novo tempo urbano para a prática e para o gozo da jardinagem. (MARX, 1980, p. 58).

Assim, enquanto a floresta brasileira, onde predomina o mistério e o desconhecido na diversidade e na mistura de espécies da flora e da fauna, passa a ocupar áreas cada vez mais reduzidas e limitadas, o jardim junto a casa, onde o homem dispõe espécies conhecidas segundo o seu gosto e a sua vontade, difunde-se tanto na área rural e semiurbana (das fazendas, dos sítios, das chácaras e rocinhas) como nas cidades. De um modo ou de outro, a paisagem transforma-se - seja pela devastação da floresta, seja pela difusão do jardim.

\section{A FLORESTA}

[...] de volta no tempo, o viajante teria olhado para um interminável tapete verde, salpicado pela glória de árvores inteiras em plena floração - a rosa-púrpura de sapucaias, o branco e o vermelho de copaíbas, o amarelo de guapiruvus, o violeta de jacarandás. Seus habitantes originais a chamavam de caá-etê, a floresta verdadeira [...] (DEAN, 1996, p. 20).

Para Dean (1996, p. 24), a história das florestas é sempre uma história de exploração e destruição, com o homem reduzindo o mundo natural à "paisagem" e a "espaço".

Quando Pedro Álvares Cabral chegou ao Brasil, em 1500, teve a visão da floresta ao longo da costa. Pero Vaz de Caminha registra esta visão na Carta a el Rei D. Manuel:

Esta terra, Senhor, parece-me que, da ponta que mais contra o sul vimos, até à outra ponta que contra o norte vem, de que nós deste porto houvemos vista, será tamanha que haverá nela bem vinte ou vinte e cinco léguas de costa. Traz ao longo do mar em algumas partes grandes barreiras, umas vermelhas, e outras brancas; e a terra de cima toda chã e muito cheia de grandes arvoredos. De ponta a ponta é toda praia... muito chã e muito formosa. Pelo sertão nos pareceu, vista do mar, muito grande; porque a estender olhos, não podíamos ver senão terra e arvoredos - terra que nos parecia muito extensa [...] (CAMINHA, 1500, p. 10, grifo nosso).

É preciso lembrar, entretanto, como salienta Dean (1996, p. 41 - 45), que, em muitos pontos, tratava-se já de uma paisagem humanizada ${ }^{3}$ pela interferência dos índios no ecossistema natural, e de uma floresta secundária ou sucessória, em função da lavoura

"A agricultura pode, portanto, ter reduzido a complexidade e a biomassa em áreas consideráveis de Mata Atlântica durante os mais de mil anos em que foi praticada antes da chegada dos europeus [...]" (DEAN, 1996, p. 46) "[...] os próprios sítios das aldeias eram grandes consumidores de floresta [...]" (DEAN, p. 52). 
itinerante e da derrubada e queimada promovidas pelos primeiros habitantes da terra, as quais eram, todavia, suficientemente limitadas, de modo a possibilitar a recuperação da floresta e o rebrotar das árvores.

Portanto, a história da devastação da floresta brasileira começa, de fato, com o descobrimento e a subsequente exploração do pau-brasil:

Em 1588, 4700 toneladas de pau-brasil passaram pela aduana portuguesa, talvez metade do verdadeiro volume. [...] Calcula-se que essa tonelagem exigiu a derrubada de aproximadamente dois milhões de árvores durante o primeiro século do tráfico (DEAN, 1996, p. 64, grifo nosso).

cultivo da cana-de-açúcar foi outro fator que contribuiu, significativamente, para a devastação da floresta:

[...] em 1700, os campos de cana-de-açúcar teriam ocupado cerca de 120 km². Esta área deve ter sido tomada da floresta, porque se achava que a cana-de-açúcar era cultivável apenas em solos de floresta. (DEAN, 1996, p. 96).

Em Nordeste..., Freyre (1989, p. 73) enfatiza esta transformação da paisagem em função do cultivo da cana, com a derrubada da mata: "Sabe-se o que era a mata do Nordeste antes da monocultura da cana: um arvoredo 'tanto e tamanho e tão basto e de tantas prumagens que não podia homem dar conta."

No século XVIII ${ }^{4}$, a descoberta do ouro também contribuiu para o processo de transformação da paisagem brasileira, não apenas pelo contingente populacional que atraiu, resultando na necessidade de maiores áreas para a lavoura e pecuária ${ }^{5}$ - e, consequentemente, na destruição de florestas ainda intocadas (DEAN, 1996, p.109) -, mas também pela alteração do relevo que a exploração do minério provocou naquele momento: alteração tão expressiva que não passou despercebida ao olhar dos viajantes europeus: "Os arredores de Vila Rica têm um caráter muito peculiar: não somente os rochedos, os vales, as cascatas the dão um aspecto selvagem, mas ainda as feridas que a exploração das minas abriu no solo por todos os lados." (RUGENDAS, 1979, p. 72).

\footnotetext{
$4 \quad$ No século XVIII, a devastação da floresta tornava-se comum por todo o país, por motivos peculiares a cada região. Nem o Sul escapava a este processo de transformação da paisagem, como observa Saint-Hilaire (1936, p. 32): "No intervalo de vinte anos, de 1763 a 1783, quando La Pérouse passou por Santa Catarina, quase nada haviam feito pelo desenvolvimento da ilha. O ilustre navegante encontrou ali uma população de 3.000 almas, sendo de 1.000 a do Desterro. O desmatamento tomara maior extensão, continuando, porém, o lugar a ser muito pobre." O próprio emprego da madeira na construção e nos móveis contribuía para a derrubada de espécies arbóreas: "A madeira que tem maior aplicação para a marcenaria é a do pau vermelho, em virtude da sua espessura que permite o fabrico de mostradores de cômodas, aparadores e cadeiras [...]" (FERREIRA [S.I.: s.n. 18-- p. 229]).

5 "No curso do século XVIII, as necessidades da população da região mineradora em termos de gêneros alimentícios, quase totalmente satisfeitas pela lavoura em regime de derrubada e queimada teriam exigido a destruição média de seiscentos quilômetros quadrados de floresta por ano [...]" (DEAN, 1996, p. 116). Warren Dean destaca, ainda, o fato de que a criação de gado, por tornar-se quase tão itinerante quanto à agricultura, " [...] para ser produtiva degradava ecossistemas primários." (DEAN, 1996, p. 131) Além disto, a criação de gado era "[...] permanentemente extensiva e expansiva e, por toda parte impedia a reversão de lavouras abandonadas à condição de floresta [...]" (DEAN, 1996, p. 131). 
Segundo Warren Dean, o ouro também era encontrado no sopé das montanhas, em determinados tipos de argila, a um ou dois metros de profundidade, e em formações rochosas friáveis:

"Nesse tipo de terreno, a floresta era queimada - grandes parcelas dela, suficientes, em certos lugares, para erradicar a lavoura itinerante [...]" (DEAN, 1996, p. 113). "O efeito desse tipo de mineração [...]", prossegue Dean, "[...] foi o de substituir a floresta por charnecas esburacadas [...]" (DEAN, 1996, p. 114) - como as observadas por Rugendas nos arredores de Vila Rica, na década de 1820.

Chega-se, portanto, ao século XIX, com uma floresta marcada pela destruição e pela devastação, com uma paisagem transformada pelo homem em grandes extensões de terra. Ainda assim, é possível encontrar referências poéticas à floresta brasileira, que resistia a este processo dramático nos relatos de viagem do século XIX6, como se observa na obra de Spix e Martius (1981, p. 139), cuja viagem ao Brasil se realizou entre 1817 e 1820: "[...] A floresta que perlonga aquelas margens já de longe se apresenta mais densa e regular, e, de perto, toda enfeitada com a maior variedade de magníficas flores, grandes e de lindas cores."

Ou no relato de Wallace (1979, p. 21), já de meados do século XIX (escrito durante a viagem de 1848 a 1849):

Penetrando-se por algumas milhas pela floresta que circunda o Pará por todos os lados, depara-se logo com um panorama diferente. Árvores de elevado porte erguem-se por todos os lados. As folhagens variam desde as mais claras e ralas às mais escuras e compactas. Trepadeiras e parasitas, com grandes folhas brilhantes, ascendem pelos troncos, chegando não raro aos galhos mais altos, enquanto outras, com seus fantásticos caules, pendem dos topos como se fossem cordas ou fios. Esparsos no solo encontram-se curiosos frutos e sementes, em número suficiente para causar espanto e admiração a todos os apreciadores da Natureza.

Data do século XIX, também, talvez uma das primeiras tentativas de reflorestamento, indicando uma preocupação com as nossas florestas. Cruls (1952, p. 373) afirma que, em 1857, a atenção do governo voltou-se para a floresta da Tijuca, no Rio de Janeiro, por serem os mananciais desta área cada vez mais aproveitados para

$6 \quad$ Há diversos outros relatos em que é possível encontrar descrições da floresta brasileira, como no texto de Bates (1979, p. 135) sobre a floresta amazônica em meados do século XIX: "[...] Toda a superfície das terras, até a beira da água, é coberta por uma uniforme e ondulante floresta verde-escuro, a caá-apoam (mata convexa) dos índios, que é característica do Rio Negro. Essa mata cobre também as extensas áreas de terras baixas que são alagadas pelo rio na estação das chuvas. [...] O grande contraste de forma e cor existente entre as florestas do Rio Negro e do Amazonas decorre das diferentes famílias de plantas que predominam em cada uma delas. Nas matas deste último, palmeiras de vinte ou trinta espécies diferentes compõem o grosso da vegetação, ao passo que no Rio Negro elas têm um papel inteiramente secundário [...]"; na Viagem pitoresca... de Rugendas (1972, p. 9): "As florestas nativas constituem a parte mais interessante das paisagens do Brasil; mas também a menos suscetível de descrição. Em vão procuraria o artista um ponto de observação nessas florestas em que o olhar não penetra além de poucos passos; as leis de sua arte não lhe permitem exprimir com inteira fidelidade as variedades inumeráveis das formas e das cores da vegetação de que ele se vê envolvido [...]"; ou no relato de Agassiz (1975, p. 131): "Desde que partimos de Manaus, a floresta se mostra menos luxuriante; é mais baixa nas margens do Solimões que nas do Amazonas, mais fragmentada, mais aberta. As próprias palmeiras são menos numerosas que antes, mas vê-se agora uma árvore que rivaliza em majestade com elas. [...] Essa árvore majestosa é a sumaúma [...]" 
o abastecimento da cidade. As fazendas, abertas cerca de trinta anos antes, e as subsequentes queimadas, haviam, praticamente, acabado com a vegetação. Mas o reflorestamento teve início apenas em 1861, quando Luís Pereira do Couto Ferraz, o Visconde do Bom Retiro:

[...] confiou ao Major Manuel Gomes Archer o grande trabalho de povoar com novas essências aquele pitoresco recanto da cidade. Para isso, Archer trouxe de sua própria fazenda [...] e também das matas que a vizinhavam, numerosas sementes e mudas dos mais vigorosos exemplares da flora fluminense. Assim, só num ano, foram plantadas, nos altos da Tijuca e das Paineiras, perto de oito mil árvores, preferentemente araribás, caneleiras, cedros, guarajubas, guaretás, guarapiapunhas, paus-brasil, jacarandás e jequitibás. (CRULS, 1952, p. 373)

Ainda nas primeiras décadas dos oitocentos, José Bonifácio de Andrada e Silva chegou a incluir em suas recomendações à delegação enviada à Corte a necessidade de obrigar os proprietários de terra "[...] a manter reservas florestais em suas propriedades [...]" - conselho ao qual não se deu nenhuma atenção naquele momento. (DEAN, 1996, p. 236)

Esta preocupação com as nossas florestas parecia estar em voga no século XIX, evidenciando-se, inclusive, em romances do período, como em Diva (1864), de José de Alencar:

Gozava-se aí de uma vista magnífica, de bons ares e sombras deliciosas. O arrabalde era naquele tempo mais campo do que é hoje. Ainda a foice exterminadora da civilização não esmoutara os bosques que revestiam os flancos da montanha. A rua, esse braço mil do centauro cidade, só anos depois espreguiçando pelas encostas fisgou as garras nos cimos frondosos das colinas. Elas foram outrora, essas lindas colinas, a verde coroa da jovem Guanabara, hoje velha regateira, calva de suas matas, nua de seus prados [...] (ALENCAR, p. 17).

Ou em A luneta mágica (1869), de Joaquim Manuel de Macedo, particularmente, no trecho em que o protagonista se encontra no Corcovado:

Fixei pois a luneta mágica sobre a cidade do Rio de Janeiro e vi... Durante os três primeiros minutos: força vital, prodígios de riqueza do solo do Império, majestade da natureza e em grande número de homens incapacidade, inveja, capricho, nepotismo, vaidade comprometendo tudo, sacrificando tudo, perdendo tudo no culto do egoísmo, e de ruins paixões [...] (MACEDO, p. 186).

Esta preocupação com as florestas e com a natureza estava perfeitamente de acordo com o romantismo brasileiro na exaltação desta natureza em função de um nacionalismo que procurava se estabelecer (CANDIDO, 2004, p. 36-37); era parte de um processo maior, de construção de uma identidade nacional, que associava a natureza a um projeto de brasilidade, estando inserida em debates mais amplos e diversificados da cultura brasileira (SANDEVILLE JUNIOR, 1999, 2010). 
Não obstante esta exaltação da natureza pelos ícones do romantismo do Brasil, o café, ao tornar-se um dos produtos das grandes fazendas, contribuiu, substancialmente, para a destruição de florestas primárias:

Nas plantações do Rio de Janeiro, plantações velhas não eram replantadas mas abandonadas, e novas faixas da floresta primária eram então limpas para manter a produção. O café avançou, portanto, pelas terras altas, de geração para geração, nada deixando em seu rastro além de montanhas desnudadas [...] (DEAN, 1996, p. 196).

Segundo Dean (1996, p. 197), enquanto em outros lugares o café era cultivado na sombra, no Brasil, florestas inteiras eram destruídas na preparação para o plantio, aplicando-se técnicas tradicionais de derrubada e queimada em maior escala. Além disto, o "[...] comércio do café induziu o crescimento demográfico, a urbanização, a industrialização e a implantação de ferrovias [...]", exercendo uma pressão ainda maior sobre as áreas florestadas no século XIX (DEAN, 1996, p. 206).

Da mesma forma que a plantação de cana levou à substituição de extensas áreas florestadas por áreas de cultivo, onde sempre prevaleceu a monotonia da monocultura, assim também o café contribuiu sobremaneira para a substituição da riqueza da diversidade da flora e da fauna por grandes áreas onde se cultivava uma única espécie. Assim, a variedade e a riqueza da floresta primária, ou mesmo secundária, deram lugar à paisagem de extensos campos plantados, consubstanciando a passagem de uma paisagem natural a uma paisagem cultural - e de cultivo.

Apesar de todo o processo de devastação, nos três primeiros séculos de colonização e ao longo do século XIX, a floresta (ou parte dela) resiste - ou tenta resistir -, permanecendo na paisagem brasileira:

Chão é um tapete de flores caídas, de todos os tons, desde o amarelo escuro, do vermelho rubro, da cor-de-rosa, até a lilás, o azul celeste e o branco alvíssimo variando com as estações, ponteiam a tapeçaria de verdura o roxo da flor-da-quaresma ou o ouro vivo do ipê [...] (PRADO, 1997, p. 12-13).

\section{O JARDIM DA CASA BRASILEIRA}

A história do jardim, não raro, pode ser associada à história da destruição da floresta, uma vez que o jardim é construído onde a floresta preexistente foi derrubada. Se a floresta representa o desconhecido, a imensidão, um jogo de luz e de sombras, de sons e silêncios, entre espécies diversificadas da flora e da fauna, no jardim o homem distribui as espécies que deseja e conhece como lhe convém. A área ajardinada é limitada e conhecida, não representa o mistério, mas um local onde a natureza se apresenta dominada pelo homem, em contraposição à floresta. Esta contradição antitética pode ser encontrada na literatura brasileira do século XIX, que registrou o processo de transformação de nossas paisagens, às vezes, a partir de lugares imaginados, mas 
correlacionados à realidade de modo simbólico ou representativo, e, outras vezes, a partir de lugares conhecidos pelo autor:

Era um edifício de harmoniosas proporções, vasto e luxuoso, situado em aprazível vargedo ao sopé de elevadas colinas cobertas de mata em parte devastada pelo machado do lavrador. Longe em derredor a natureza ostentava-se ainda em toda a sua primitiva e selvática rudeza; mas por perto, em torno da deliciosa vivenda, a mão do homem tinha convertido a bronca selva, que cobria o solo, em jardins e pomares deleitosos, em gramais e pingues pastagens, sombreadas aqui e acolá por gameleiras gigantescas, perobas, cedros e copaíbas, que atestavam o vigor da antiga floresta. Quase não se via ali muro, cerca, nem valado; jardim, horta, pomar, pastagens, e plantios circunvizinhos eram divididos por viçosas e verdejantes sebes de bambus, piteiras, espinheiros e gravatás, que davam ao todo o aspecto do mais aprazível e delicioso vergel. (GUIMARÃES, 1875, p. 11).

Houve casos, no entanto, ainda que raros, em que o jardim se aliou à floresta, com um resultado esfuziante ao olhar do viajante estrangeiro, como relata Avé-Lallemant (1980, p. 37) em sua viagem pelo rio Amazonas, realizada em meados do século XIX:

[...] Essa casa, rodeada de dois lados por uma varanda, é tão larga que forma duas salas conjugadas abertas em volta. Ao lado, um jardim conquistado à floresta virgem, onde diversos grupos de astrocárias, providas de espinhos, uma gutífera parasita, alta e viçosa, asfixia uma palmeira; um enorme eriodendro e uma palmeira pupunha falam da floresta, enquanto flores de jardim, cuidadosamente tratadas, espalham longe seu perfume. Desse belíssimo belvedere goza-se de todo o panorama do rio a jusante, do rio a montante e do rio defronte, em cuja margem, uma ilha após outra velam parte da colossal largura do Tocantins. Tudo isso moldurado pela orla encantadora da floresta, tendo por cima um céu profundamente azul, cuja límpida abóbada parece suportada pelos troncos-pilastras das miritis. Essa a minha pousada de Páscoa, na extremidade mais baixa de Cametá, tão encantadora como nunca possuíra igual.

Isto ao norte do país, onde a floresta equatorial era soberana em relação ao jardim cultivado pelo homem, que não tinha mesmo como competir em escala e proporção com a imensidão das áreas florestadas do entorno. Nas áreas mais interioranas, assim como ao longo da costa leste, o jardim, muitas vezes, constituiu-se apartado da floresta, "[...] plantado de laranjeiras, limoeiros, goiabeiras, cajueiros e tamarindeiros [...]", como registra Florence (1977, p. 137) em relação a Cuiabá, em viagem realizada entre 1825 e 1829.

Em princípios do século XIX, o jardim da casa brasileira apresentava ainda as características do período colonial, com árvores de fruto misturadas às flores, às ervas e aos legumes. Neste jardim, ainda predominava o sentido útil, em detrimento do valor estético (FREYRE, 2006; ARAGÃO, 2008). Mesmo nas cidades litorâneas era possível encontrar jardins juntos às casas, plantados com laranjeiras - como o que aparece no 
anúncio publicado no Diário do Rio de Janeiro, em sete de janeiro de 1822, da casa de vivenda situada no caminho novo do Botafogo. As árvores do jardim, na maioria das vezes, não correspondiam às árvores da floresta nativa, e, sim, àquelas conhecidas pelos europeus e transplantadas para o Brasil durante os três primeiros séculos de colonização.

É no mínimo interessante constatar que nem mesmo um movimento como o romantismo, com toda a repercussão que teve na sociedade brasileira, levou as flores da floresta para o jardim. Ao contrário, difundiam-se, nas áreas ajardinadas, rosas e camélias, denunciando a valorização das flores comuns ao jardim europeu ao invés das tropicais. Estas quem valorizou foram os estrangeiros, que colecionavam flores tropicais pela sua beleza e singularidade?.

Este jardim de rosas e camélias, aos poucos, passou a apresentar, ao menos, a busca ou a intenção de um valor estético - tanto na frente das residências urbanas, como nas chácaras nos arredores da cidade ou nos espaços públicos que receberam tratamento paisagístico. Cabe, então, perguntar o que significou esta mudança no jardim para a paisagem brasileira do século XIX. Por um lado, estava de acordo com um contexto de europeização que se estabeleceu desde a chegada da Corte ao Rio de Janeiro em 1808 - contexto em parte contraditório à exaltação da natureza brasileira e à valorização de nossas paisagens propostas pelos poetas e escritores do romantismo. Por outro lado, consolidou, na paisagem, a presença de plantas exóticas, enquanto os estrangeiros cultivavam espécies tropicais em seus jardins, e paisagistas (como Glaziou) vindos de outros países incluíam exemplares da flora nativa em seus projetos, promovendo a mistura do nativo e do exótico nos arranjos florísticos e na composição arbórea. Enquanto diversas espécies desapareciam nas queimadas subsequentes da floresta, o jardim dava abrigo a outras plantas, ratificando este processo de transformação da paisagem brasileira - que, a partir do século XIX, se torna irreversível, como sublinha Dean (1996, p. 206). Nem mesmo no jardim se preservou ou se pretendeu preservar a riqueza da flora nativa - intenção esta que, certamente, teria conferido características muito diversas às nossas paisagens nos oitocentos.

\section{A FLORESTA E O JARDIM DA CASA BRASILEIRA DO SÉCULO XIX}

À primeira vista, o Brasil poderia ter se apresentado aos europeus como um imenso jardim. Mas, aos portugueses, interessou muito mais o valor econômico da floresta. Em momento algum se pensou em preservar a paisagem verdejante das terras tropicais recém-descobertas. Ao contrário, pensou-se na exploração do pau-brasil para obtenção

\footnotetext{
Por outro lado, é preciso lembrar que o desejo dos estrangeiros, colecionar plantas tropicais, nem sempre teve aspectos favoráveis. Parte da floresta nativa foi derrubada em função da extração de determinadas espécies: "[...] As epífitas desejadas pelos agentes comerciais ingleses, belgas, franceses e alemães se aninhavam nos galhos das árvores mais altas da Mata Atlântica. A única maneira prática de obtê-las era cortar as árvores." (DEAN, 1996, p. 179). Assim, a própria apreciação das espécies tropicais levou à derrubada de árvores para sua remoção e venda no exterior.
} 
de lucro, no plantio da cana, na busca do ouro. Quando se tomavam medidas para conter a derrubada da floresta, era no sentido estrito de preservar os recursos para que não cessasse o lucro.

A devastação da floresta brasileira representa, de fato, uma das mais expressivas transformações de nossas paisagens - floresta transformada em espaço vazio, descampado, floresta transformada em extensos campos cultivados e, em seguida, abandonados, floresta transformada em paisagem monótona, que garante a lucratividade pela produção. Floresta, também, que cede lugar ao jardim junto a casa brasileira, nas áreas rurais e urbanas, ou, no meio termo, entre o campo e a cidade. Jardim que não abriga as árvores e flores da floresta, mas as espécies exóticas advindas de outras paisagens, que transformam a nossa paisagem.

O século XIX, como vimos, é marcado pela consolidação deste processo de transformação, ao mesmo tempo em que vê nascer uma preocupação com as nossas florestas e uma valorização da natureza brasileira, que, no entanto, não foram suficientes para impedir a devastação das áreas florestadas, nem tampouco para convencer os próprios brasileiros (ou, pelo menos, a maior parte deles, com raras exceções) da beleza da flora nativa.

Assim, o jardim da casa brasileira do século XIX não abriga, em sua maior parte, as árvores e flores da floresta, mas as espécies exóticas advindas de outras paisagens, que transformam a nossa paisagem nesse processo de substituição da flora nativa (ainda pouco valorizada pelos brasileiros nesse momento) pelas plantas valorizadas pelos europeus, seja por seu sentido útil (especialmente durante o período colonial e nas primeiras décadas do século XIX), seja por seus aspectos ornamentais (principalmente, a partir da chegada da Corte em 1808 e da abertura dos portos às nações amigas, que possibilita uma influência mais acentuada da França e da Inglaterra em nossa paisagem habitada, em nossas casas e jardins).

\section{REFERÊNCIAS BIBLIOGRÁFICAS}

AGASSIZ, Louis; AGASSIZ, Elisabeth. Viagem ao Brasil: 1865-1866. Tradução de João Etienne Filho. São Paulo: Edusp, 1975.

ALENCAR, José de. Diva (1864). Texto proveniente da Fundação Biblioteca Nacional. Disponível em: <http://www. dominiopublico.gov.br>. Acesso em: 25 jun. 2011.

ARAGÃO, Solange de. Ensaio sobre o jardim. São Paulo: Global, 2008.

AVÉ-LALLEMANT, Robert. No rio Amazonas (1859). Tradução de Eduardo de Lima Castro. São Paulo: Edusp, 1980. Publicado originalmente em 1859.

BATES, Henry. Um naturalista no rio Amazonas (1850-1851). Tradução de Regina Régis. São Paulo: Edusp, 1979.

CAMINHA, Pero Vaz de. Carta a el Rei D. Manuel (1500). Texto proveniente da Biblioteca Virtual do Estudante Brasileiro. Disponível em: <http://www.dominiopublico.gov.br>. Acesso em: 2 mai. 2011.

CANDIDO, Antonio. O romantismo no Brasil. 2. ed. São Paulo: Humanitas, 2004.

CRULS, Gastão. Aparência do Rio de Janeiro (notícia histórica e descritiva da cidade). Rio de Janeiro: José Olympio, 1952. 
DEAN, Warren. A ferro e fogo: a história e a devastação da mata atlântica brasileira. São Paulo: Companhia das Letras, 1996.

FERREIRA, Alexandre Rodrigues. Viagem filosófica ao rio Negro [SI.: sn. 1787]. Belém: Museu Emilio Goeldi, s.d. FLORENCE, Hercules. Viagem fluvial do Tietê ao Amazonas (1825-1829). Tradução de Visconde de Taunay. São Paulo: Edusp, 1977.

FREYRE, Gilberto. Nordeste: aspectos da influência da cana sobre a vida e a paisagem do Nordeste do Brasil. 6. ed. Rio de Janeiro: Record, 1989.

Sobrados e mucambos: decadência do patriarcado rural e desenvolvimento do urbano. 16. ed. São Paulo: Global, 2006. Originalmente publicado em 1936.

GUIMARÃES, Bernardo. A escrava Isaura (1875). Texto proveniente da Biblioteca Virtual do Estudante Brasileiro. Disponível em: <http://www.dominiopublico.gov.br>. Acesso em: 25 jun. 2012.

MACEDO, Joaquim Manuel de. A luneta mágica (1869). Texto proveniente da Fundação Biblioteca Nacional Disponível em: <http://www.dominiopublico.gov.br>. Acesso em: 24 jun. 2011.

MARX, Murillo. Cidade brasileira. São Paulo: Melhoramentos, 1980.

PRADO, Paulo. Retrato do Brasil: ensaio sobre a tristeza brasileira. São Paulo: Companhia das Letras, 1997. Publicado originalmente em 1928.

RUGENDAS, Johann Moritz. Viagem pitoresca através do Brasil. São Paulo: Edusp, 1972.

Viagem pitoresca através do Brasil. Tradução de Sérgio Milliet. 8. ed. São Paulo: Edusp, 1979.

SAINT-HILAIRE, Auguste de. Viagem à província de Santa Catarina (1820). São Paulo: Companhia Editora Nacional, 1936.

SANDEVILLE JUNIOR, Euler. As sombras da floresta: vegetação, paisagem e cultura no Brasil. 1999. 371 f. Tese (Doutorado em Estruturas Ambientais Urbanas) - Faculdade de Arquitetura e Urbanismo da Universidade de São Paulo, São Paulo, 1999

Sobre a construção de uma natureza tropical brasileira, 2010. Inédito.

SPIX, Johann Baptist von; MARTIUS, Karl Friedrich Philipp von. Viagem pelo Brasil: 1817-1820. Spix e Martius. Tradução de Lúcia Furquim Lahmeyer. São Paulo: Edusp, 1981.

WALLACE, Alfred Russel. Viagens pelos rios Amazonas e Negro (1848-1849). Belo Horizonte: Itatiaia, 1979. 
